\title{
Prediction of the Beach Profile of High-Density Thickened Tailings from Rheological and Small-Scale Trial Deposition Data
}

\author{
G.I. McPhail Metago Environmental Engineers (Australia) Pty Ltd, Australia
}

\begin{abstract}
Prediction of the beach profile of tailings using stream power has been in application for conventional tailings since 1995. Extension of this methodology to high density thickened tailings has been evaluated through the scaling up of flume testing as well as in the prediction of beach profiles from raw rheological data. This paper describes the stream power methodology and the results of the evaluations.
\end{abstract}

\section{Introduction}

High density thickened tailings deposition is acknowledged as offering significant benefits over deposition at conventional slurry consistencies as regards operating cost, water savings, seepage minimisation and decommissioning. It is also possible to gain the majority of the scale of benefits by thickening only to a consistency which allows the discharged slurry stream to flow into position without the need for mechanical assistance. A key question, however, when designing a high density thickened tailings facility, is that of the beach profile of the deposited mass.

In 1995, this author completed research into the application of stream power and entropy to the prediction of beach profiles as well as the particle size distribution down the beach. This research focused on conventionally thickened tailings as development of the technology for generating high density thickened tailings was still in its infancy at the time of the research. It was shown, through the evaluation of uranium, platinum, copper, lead zinc and gold tailings, ie. a range of mineral residues of varying particle specific gravity, that entropy-stream power predictions offered a viable methodology for predicting beach profiles.

But will the methodology work for high density thickened tailings, and if so, how could it be applied?

These questions are addressed in this paper which will begin by describing the essence of the entropy-stream power approach and move through the application of this approach to beach prediction using data obtained from small-scale flume and pilot-scale trial deposition tests.

\section{Description of the entropy-stream power approach}

There are a number of approaches that could be taken towards the development of a beach prediction methodology. Two of the most common are:

- The application of two dimensional hydrodynamics in which equations describing the flow characteristics of the slurry stream in the horizontal and vertical axes are developed. Application of this approach in pipe and open channel flow design for water is standard practice but, in respect of slurry systems has variable reliability owing to the complexity of accounting for inertial, gravity and viscous forces in a dynamic system. Attempts to apply this approach to loose boundary problems involving slurries has had limited success.

- The application of empirical approaches involving curve fitting and correlation of the main variables through established hydraulic equations. This method has been shown to yield good results for slurries for which there is a reasonable volume of data but shows limitations when attempting to apply the method to predictions for slurries for which data are very limited. 
A further, and newer approach, is that entailing entropy and stream power. This methodology is not based on constitutive equations developed from first principles but rather has its foundations in the following observations:

- Many natural phenomena can be described using entropy-maximisation. These range from electronic signal transmission to river profiling. Indeed it has been shown that the methodology can be applied with a high degree of representativeness to the natural deposition of a slurry in a loose boundary situation (McPhail, 1995).

- In order for particles in the slurry to remain in suspension and be transported down the beach it is necessary to overcome gravitational forces, that drag the particle downwards, and frictional and viscous forces, that slow the particle down. As soon as a mass is moved over a distance under the resistance of a force energy is consumed. To determine the ability of a slurry to flow, therefore, it is necessary to determine the energy contained within the flow stream.

- Stream power represents the energy per unit of time consumed by the particles in remaining in suspension as they move along the beach. Since the discharge flow rate remains essentially constant stream power at any point along the beach is likely to be consistent with time.

Stream power is calculated from the multiplicand of density $(\rho)$, flow rate $(Q)$ and the energy head $(H)$ in the equation:

$$
P=\rho g Q H
$$

If the beach profile is taken as the datum the head, $H$ in Equation (1), at any point along the beach will be equal to the velocity head, v2/2 g since in a loose boundary open channel system there is no pressure head. The stream power at any point at a distance of $x$ from the start of the beach may therefore be written as:

$$
P_{x}=\rho Q g\left(\frac{v_{x}^{2}}{2 g}\right)=\rho q \frac{v_{x}^{2}}{2}
$$

The difference in elevation between a point on the beach at a distance $\mathrm{x} 2$ from the discharge relative to a point at a distance $\mathrm{x} 1$ will be equal to the change in velocity head from $\mathrm{x} 2$ to $\mathrm{x} 1$. If $\mathrm{x} 2$ and $\mathrm{x} 1$ are sufficiently close to one another that the density and flow rate may be considered constant between them then the change in velocity head is equal to the change in stream power (Equation (1)). Moreover, the slope of the beach will be equal to the slope of the velocity head curve which will, in turn, be equal to the slope of the stream power curve. This means that, provided changes in stream power can be estimated along the beach, the slope of the beach can be determined at any point.

It was postulated by McPhail (1995) that an entropy maximisation approach could be used to estimate the stream power at any point along the beach. He evaluated this for a wide range of conventionally thickened tailings products over a range of beach lengths from laboratory flume size to $1.2 \mathrm{~km}$. It was found that beach profiles calibrated using the entropy-based stream power approach gave good approximations of the measured beach profiles.

In essence entropy maximisation applied to stream power means that of the infinite number of curves that could define the change in stream power from a maximum at the head of the beach to zero at the end of the beach the one described by Equation (3) has the highest probability of describing reality.

Using entropy maximisation (McPhail, 1995) derived the following equations for stream power $\mathrm{P}$ at any point located a distance $\mathrm{x}$ from the start of the beach as:

$$
P(x)=-\frac{1}{\mu} \ln \left[\left(1-\exp ^{-\mu P_{0}}\right) \frac{x}{L}+\exp ^{-\mu P_{0}}\right]
$$

The parameter $P_{0}$ is the stream power at the start of the beach. $L$ is the distance from the start of the beach to the edge of the supernatant pond where the residual stream power will be dissipated and brought to zero. The parameter $\mu$ is a constant emerging from the mathematical derivation of equation (3). 
The slope at the start of the beach is obtained by differentiating Equation (3) with respect to $\mathrm{x}$ to obtain $\mathrm{S}_{0}$ which yields the following equation:

$$
S_{0}=-\frac{\left(1-\exp ^{-\mu P_{0}}\right)}{L \mu \exp ^{-\mu P_{0}}}
$$

It follows that a knowledge of the stream power at the start of the beach will enable the determination of $\mu$ from Equation (4).

The slope of the stream power curve, $S_{B}(x)$ and hence of the beach can be determined at any point, $x$, along the beach from the equation:

$$
S_{B}(x)=-\frac{\left(1-\exp ^{-\mu P_{0}}\right)}{L \mu \exp ^{-\mu P(x)}}
$$

The elevation, $y$, of the beach at any point, $x$, along the beach can be determined using the following equation and working in small increments of $\Delta x$ from the start of the beach:

$$
y=y(x+\Delta x)+S_{B}(x) \Delta x
$$

Equation (6) gives the beach profile.

\section{Applying entropy and stream power}

The application of Equations (1) to (6) requires the following information:

- The elevation of the beach at the start of the beach profile.

- The length of the beach.

- Slurry density.

- Slurry flow rate.

- An estimate of the stream power at the start of the beach.

- An estimate of the initial slope of the beach.

The first four points are simple and a function of the operation and mine site, but the last two merit detailed discussion.

\subsection{Estimating the stream power at the start of the beach}

The stream power at the start of the beach is not equal to the stream power in the pipe. Pipe flow is set up to maintain solids in suspension within the pipe walls. Once the walls are removed, and the flow stream is allowed to find its own natural flow characteristics, the flow velocity will change. Initially it will increase, depending on the height of the pipe above the beach, as the flow stream goes into free-fall. Under these conditions it is likely that the flow stream will be super-critical which will generate a plunge pool below the pipe when the stream contacts the beach. Within the plunge pool there will be a hydraulic jump and flow will move from super to sub-critical. Depending on the slurry density and flow rate there may be a move back to supercritical as the flow stream exits the plunge pool and sets off down the beach. This will result in a series of hydraulic jumps down the beach until the flow rate and slurry density are such that the flow remains subcritical. For higher density slurries it is more likely that flow will remain laminar as it exits the plunge pool. Any non-uniform flow observed beyond the plunge pool will then likely be the result of small fluctuations in slurry density, which will result in a rippled, uneven flow channel.

Standard hydraulics can be used to calculate the jet stream from the pipe to the plunge pool as well as the relative depths of flow of super and sub-critical elements within the plunge pool (Webber, 1971). It is vital to ensure that realistic estimates of the pressure near the end of the pipe are available. This is because as the slurry leaves the pipe the residual pressure head is converted to velocity head resulting in an increase of 
slurry velocity and a consequent reduction in the diameter of the flow stream out of the end of the pipe. This increased velocity will strongly influence the results of the hydraulic calculations in the plunge pool.

In carrying out the plunge pool hydraulic calculations it is necessary to make an assumption as to the flow channel geometry. It is reasonable to assume a semi-circular flow section for the flow stream as this represents the maximum hydraulic radius (flow area divided by the flow perimeter) and therefore the channel section with the least flow resistance. Natural systems tend to minimise flow resistance in this manner.

\subsection{Estimation of the initial slope of the beach}

Estimation of the initial slope of the beach requires knowledge of the friction flow characteristics of the slurry. These characteristics, in turn, depend on the rheology of the slurry and specifically the relationship between shear stress within the flowing slurry and the shear rate.

In pipe flow calculations for a slurry it is common to carry out viscosity testing to determine rheograms which describe the characteristic relationship between shear rate and shear stress. Usually the primary requirement for pipeline design is to ensure that the slurry does not settle out in the pipe so the emphasis in carrying out rheological testing is one of considering shear rates that correlate with velocities above $1 \mathrm{~m}$ per second. Even then, testing of non-homogenous slurries that settle out in the rheometers renders the rheological measurements unreliable.

In the beaching situation, however, the material is naturally setting out. Measurement of the rheology of a settling slurry under these conditions by means of standard testing methods is exceedingly problematic and unreliable.

This is one of the reasons tailings engineers eagerly look to small scale beach testing in flumes. Other reasons relate to complexity and uncertainty in the reliability of calculations based on rheological models and the relative ease with which a range of slurry densities can be tested compared with full scale operations.

However, many tailings engineers have had bad experiences with flumes when extrapolating to the full scale situation and there is a lingering question of how best to make use of the flume test results.

This author has considered the results of small scale flume tests and arrived at the following conclusions:

- Useful data can be obtained from small-scale flume testing if analysed correctly.

- The scale on which small-scale flume tests are carried out (frequently flumes of less than $3 \mathrm{~m}$ are used) is such that neither the energy gradient over the length of the beach, nor the shear rate of the slurry at the start of the beach, approximates the field condition. This is because, to achieve this, minute flow rates would be required necessitating discharge pipes of less than $10 \mathrm{~mm}$. These pipe sizes are impractical for most slurries as they would simply choke up.

- Generally the small scale flumes have channel widths of 0.3 to $0.5 \mathrm{~m}$. These widths result in significant edge effects as evidenced by the curved flow lines that are most commonly observed in the flumes during deposition.

- It is difficult to control the supernatant pond. Some pond depth is essential in the testing in order to ensure that the flow is reduced to zero and is therefore representative of the field situation. A small change in pond depth often results in a drastic reduction in beach length in the flume thereby exacerbating the scale problems noted above.

This author is of the opinion that a trial deposition paddock with beach lengths of $8 \mathrm{~m}$ or more will yield better results than a small scale flume test. By discharging into a corner of the paddock the depositing mound will be allowed to flow naturally to its own geometry with minimal interference from side walls. At this scale it is more practical to effect realistic pond control. In setting up these tests, however, it is important to:

- Control flow rates such that there is parity between the anticipated full scale energy gradient along the beach.

- Ensure that discharge conditions result in shear rates in the slurry that are as close to the field situation as possible. 
Unfortunately it is not always practical to carry out deposition testing at a laboratory on the above scale. Often it is necessary to set up the paddocks at the mining operation and this limits the range of slurry densities over which testing can be carried out.

The method for estimating the initial slope of the full scale beach from small-scale flume or pilot-scale trial deposition testing is as follows:

- For each test at a given slurry density measure the beach profile, and discharge rate and apply equation to calibrate the initial beach slope that will result in the closest approximation of the beach profile in the flume. This is carried out by varying $P_{0}$ and the initial slope until the best fit is obtained.

- Calculate the shear rate from the calibrated stream power by using Equation (2) to determine the stream velocity, continuity to determine the flow depth for a semi-circular flow section, and the following equation for shear rate:

$$
\omega=8 v / R
$$

where $R$ is the hydraulic radius of the flow stream at the lip of the plunge pool.

- Calculate the shear stress from the calibrated initial beach slope using the following equations (Wasp et al., 1977)

$$
\tau=f \rho v / 2
$$

where $f$ is the Fanning friction coefficient.

$$
S_{B}=4 f v^{2} / 2 g R
$$

where $S B$ is the friction slope at the lip of the plunge pool ie the initial beach slope.

- Plot the shear stress versus the shear rate for the range of slurry densities.

- Use the full scale discharge data of slurry density, flow rate, pipe diameter, and residual pressure together with standard hydraulic calculations for the plunge pool to estimate the initial stream power in the field condition and from this the shear rate using the above equations.

- Using this shear rate interpolate an estimate of the shear stress from the plot of shear stress and shear rate derived from the trial deposition testing.

- Apply this shear stress to Equations (8) and (9) to derive the initial beach slope.

In applying the above methodology the following will have been achieved:

- Each small or pilot-scale deposition will have effectively served as a rheometer from which point estimates of the characteristic relationship between slurry density, slurry shear rate and resulting shear stress would have been obtained. In the case of a carefully designed pilot-scale test the results would be representative of the full scale deposition system in that the same settling rates and mechanisms would be at work as in the full scale operation.

- The entropy-stream power methodology would have been applied in calibrating the trial depositions as well as in the full scale calculations so that scaling is carried out on the basis of the main controlling factors of stream power, as determined by the discharge characteristics (flow rate and velocity), beach length, and friction slope at the start of the beach (initial beach slope).

Two case studies that illustrate the above methodology are presented below.

\section{Case studies}

\subsection{Case study 1: Scaling from flume measurements to full scale}

This case study entails a slurry of solids SG 3.6, a maximum particle size of $1.18 \mathrm{~mm}$ and a percentage passing $0.075 \mathrm{~mm}$ of $50 \%$. The slurry was generated by hard rock mining. 
Flume tests were carried out in a flume constructed directly adjacent to a pipe loop. At the end of a pipe loop test of a slurry at a particular density a portion of the flow stream was diverted to the flume. The flume measured $7 \mathrm{~m}$ long by $0.5 \mathrm{~m}$ wide. Discharge was through a $25 \mathrm{~mm}$ pipe at a flow rate of $0.8 \mathrm{l} / \mathrm{s}$ such that the pipe was parallel to the beach and close to the beach elevation. The pipe was slowly raised as the beach built up.

Figure 1 shows the measured beach profiles in the flume tests. Also indicated are fitted profiles based on the stream power equations described above.

It is evident from Figure 1 that the entropy-stream power beach profiles fit the flume measurements exceedingly well.

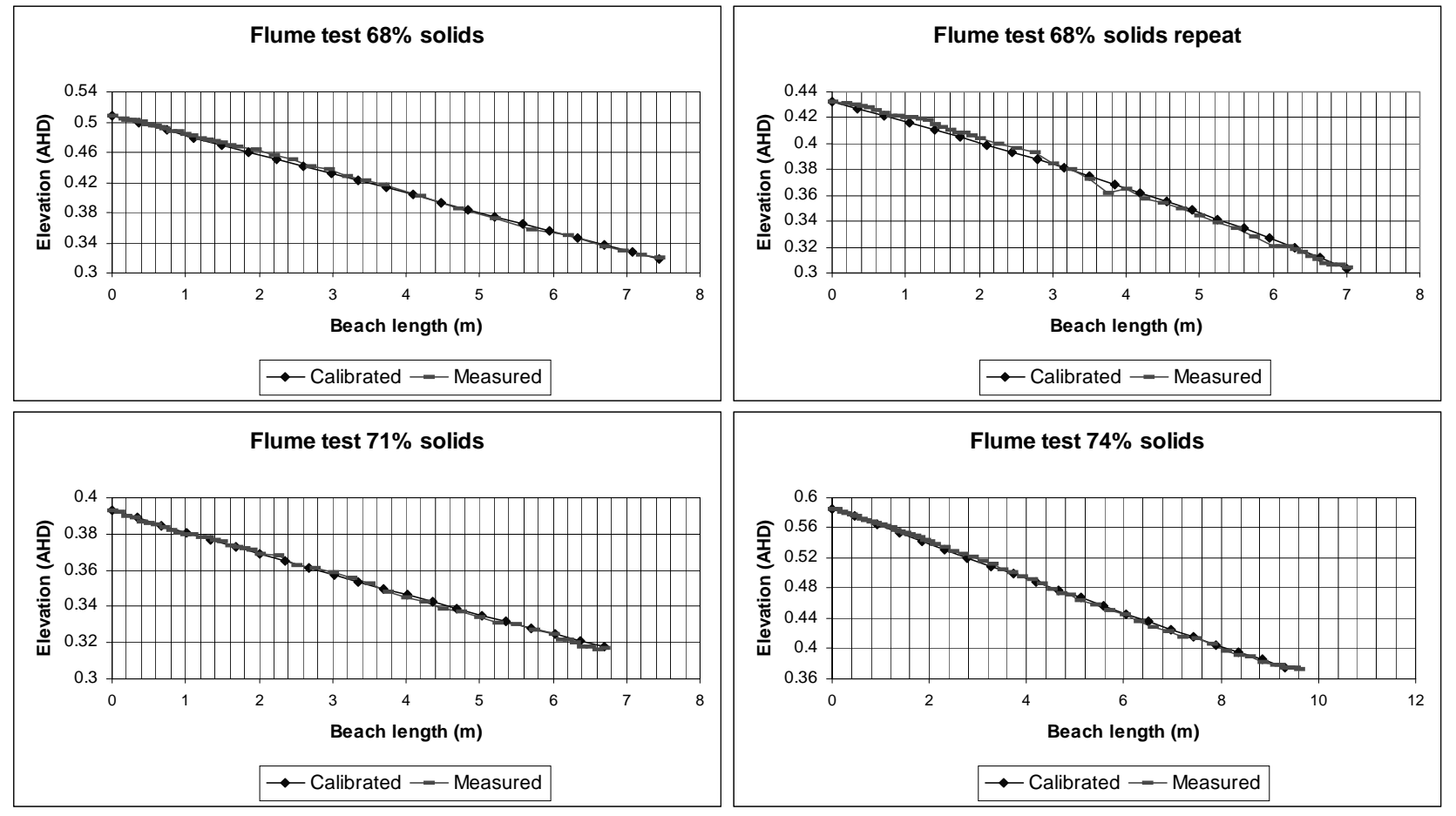

\section{Figure 1 Measured and fitted beach profiles for the flume tests}

Figure 2 shows measured beach profiles from the full-scale field operations. These have been measured over the period from 2000 to 2004 and cover the pre-high density operations and three trial depositions all carried out in the course of routine operations as modifications to the thickening equipment were progressively implemented. Also indicated are the fitted profiles using the entropy-based stream power methodology as well as the calibrated stream power, shear rate, shear stress and fitted initial beach slope. Once again it is evident that the entropy-stream power beach profiles closely approximate the measured profiles.

Figure 3 shows plots of the shear stress versus shear rate for the flume and the full scale tests derived using Equations (7) to (9). Indicated are also two power law curves which have been fitted through data points from the flume tests and the full-scale tests that are at the same slurry consistency/density.

Figure 4 shows the results of viscosity testing on slurries made up of the minus $0.075 \mathrm{~mm}$ fraction of the tailings. This size fraction was tested so as to reduce the problems associated with setting out of the slurry. As can be see from the annotations on Figure 4 the slurry was still settling out during the testing. 

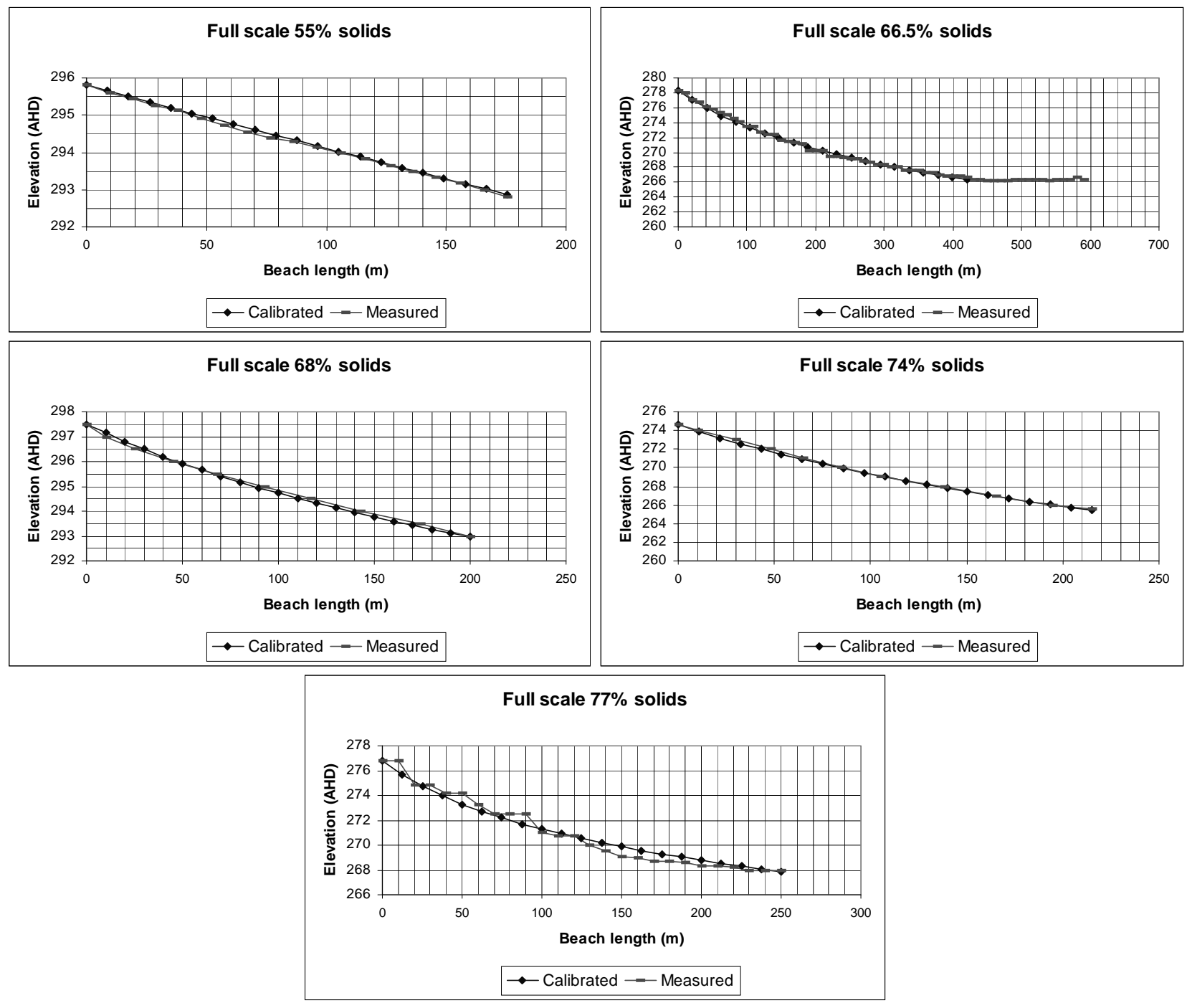

Figure 2 Measured and fitted beach profiles from full scale measurements of the actual operation

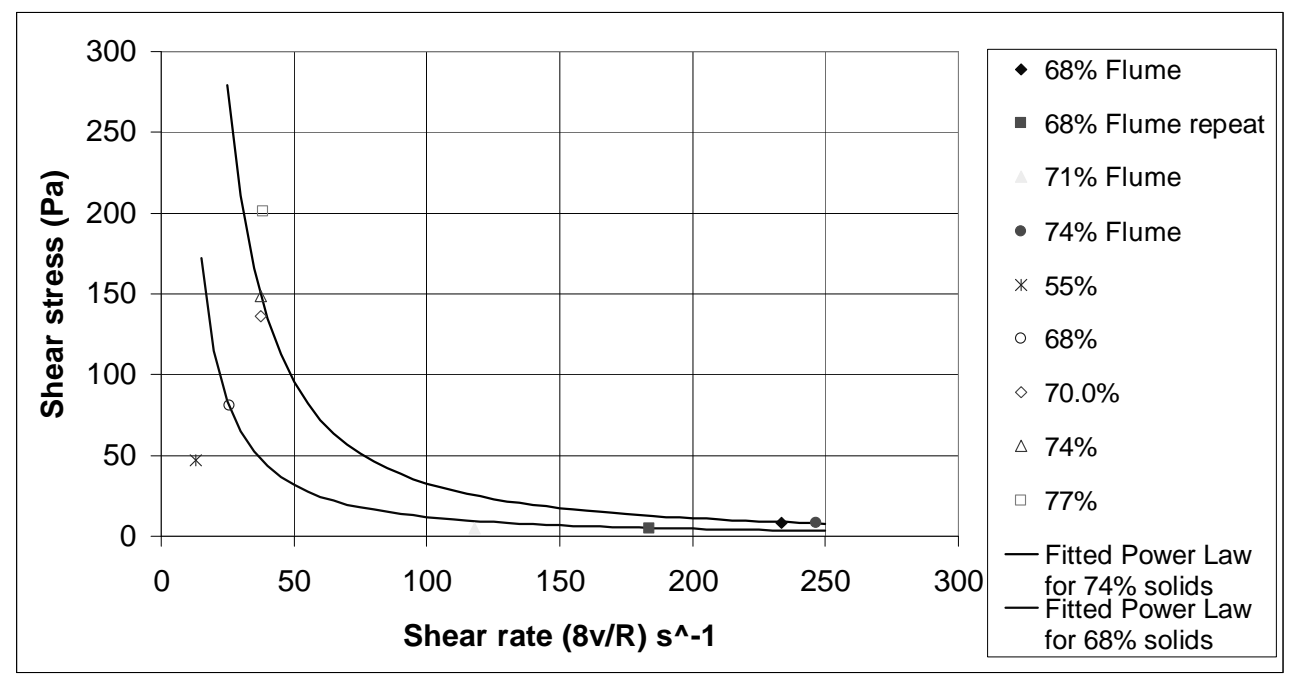

Figure 3 Plots of shear stress versus shear rate for the flume and full-scale situations 


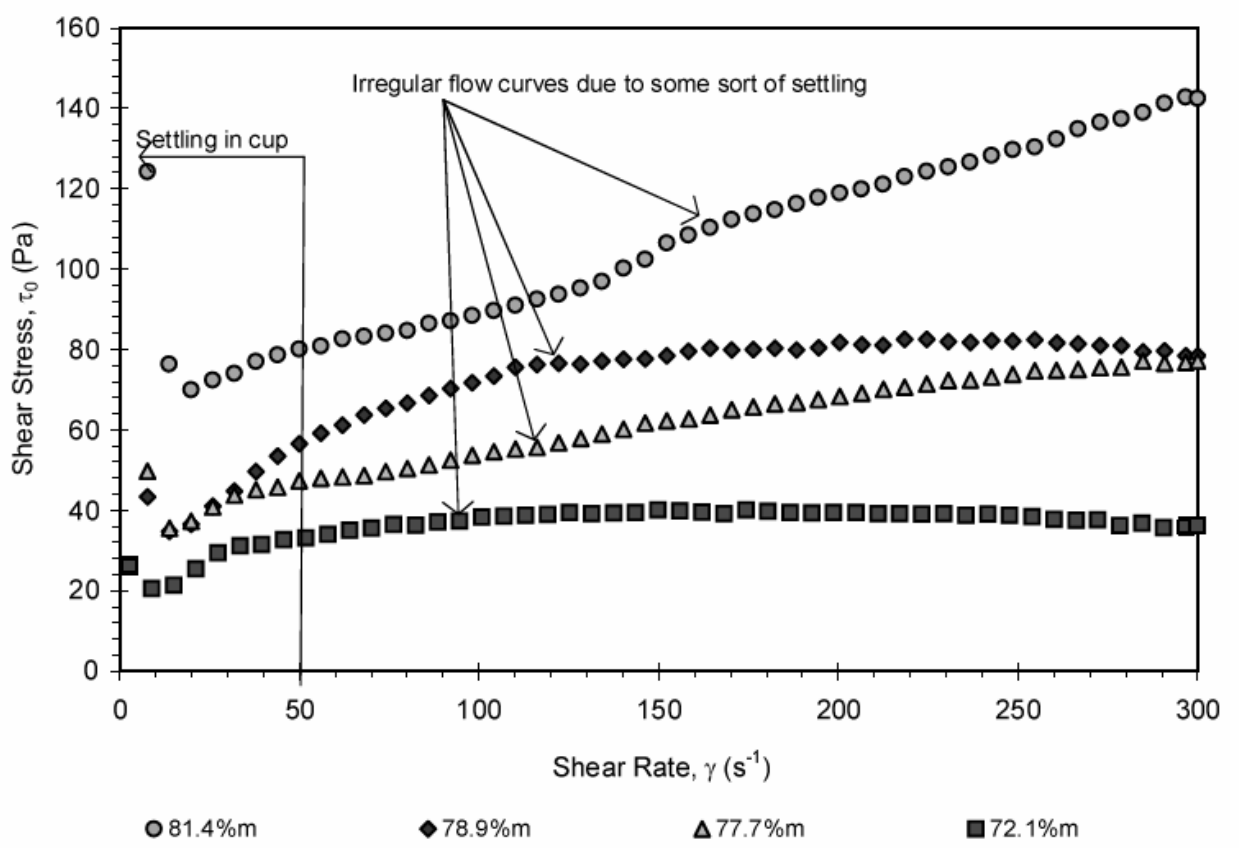

Figure 4 Rheograms of shear stress versus shear rate from rotary viscometer testing

The following points are noteworthy in respect of the above results:

- The axes of the graph in Figure 3 are the same as those in a rheogram. As such the rising shear stress at decreasing shear rate would seem to be at variance with almost all rheograms indicated in the literature. However, it needs to be borne in mind that the measurements indicated are of a settling slurry on a loose, aggrading boundary. As the shear rate decreases so the settled, liquefied, material more closely approaches a sedimented, non-liquid, material. At a shear rate of zero the shear stress is likely to be equal to the shear strength of the newly settled tailings and this is always going to be higher than the flowing, liquefied, tailings.

- The above observations and conclusions are borne out by the viscosity testing results indicated in Figure 4. It is evident that the slurry in-homogeneity is strongly affecting the results at shear rates of less than $20 \mathrm{~s}-1$. The results mirror those of Figure 3 in this shear rate range in that the shear stress is increasing as the shear rate tends to zero.

- The beach profile fits are exceptionally good in both the small scale as well as the full scale tests and across the full range of slurry densities from conventional (55\% solids) to high density (78\% solids).

- The flumes have significantly higher shear rates and lower shear stresses than the full scale operations. This is ascribed to the relatively high velocities in the flumes, a result of delivery pipe size limitations as discussed in Section 3.2.

- If the flume tests could be set up such that the shear rate and shear stress were close to those that occur in the full scale operations the degree of error in extrapolation from flume to full scale would be significantly decreased. It would be prudent, however, to ensure that the width of the flume is wide enough to minimise edge drag effects.

\subsection{Case study 2: Scaling from pilot-scale trial depositions}

Case study 2 describes pilot scale trial depositions of a slurry with a maximum particle size of $3.35 \mathrm{~mm}$, a percentage passing $0.075 \mathrm{~mm}$ of $15.5 \%$ and a particle SG of 2.7. Consideration is being given to implementing high density thickened deposition of these tailings and, for planning purposes, the question arises as to what beach profile may be expected. 
Thickening equipment and materials handling limitations suggest that a maximum practical density to which the tailings could be reliably thickened is $1.9 \mathrm{t} / \mathrm{m}^{3}$. It was therefore decided to carry out two pilot scale tests on paddocks of approximately $12 \times 12 \mathrm{~m}$ with discharge taking place in one corner of each paddock to allow the depositing cone to form without influence from side walls. A pond was allowed to form such that the beach length was not less than $5 \mathrm{~m}$. In the test with the lower density slurry the paddock sloped downwards and away from the discharge point whereas in the higher density test the paddock sloped upwards from the discharge point. This, together with the difference in flow rates and plunge pool formations which determine the initial stream power and shear rate, accounts for the differences in the beach profiles.

Figure 5 shows the measured and fitted beach profiles for the trials.
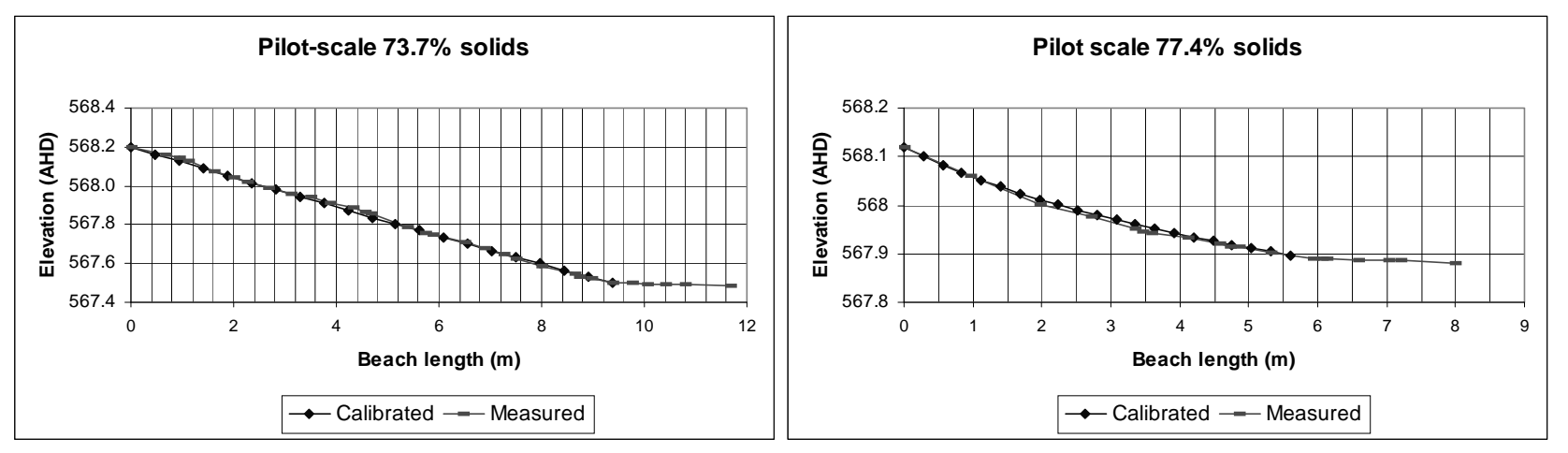

Figure 5 Measured and fitted beach profiles from the trial depositions

Figure 6 shows a plot of the shear stress versus shear rate results from the two pilot-scale tests. An estimate for the shear stress at a shear rate of $6.82 \mathrm{~s}^{-1}$ is indicated for the $73.7 \%$ solids $\left(1.8 \mathrm{t} / \mathrm{m}^{3}\right)$ slurry. A power law curve has been applied to the results.

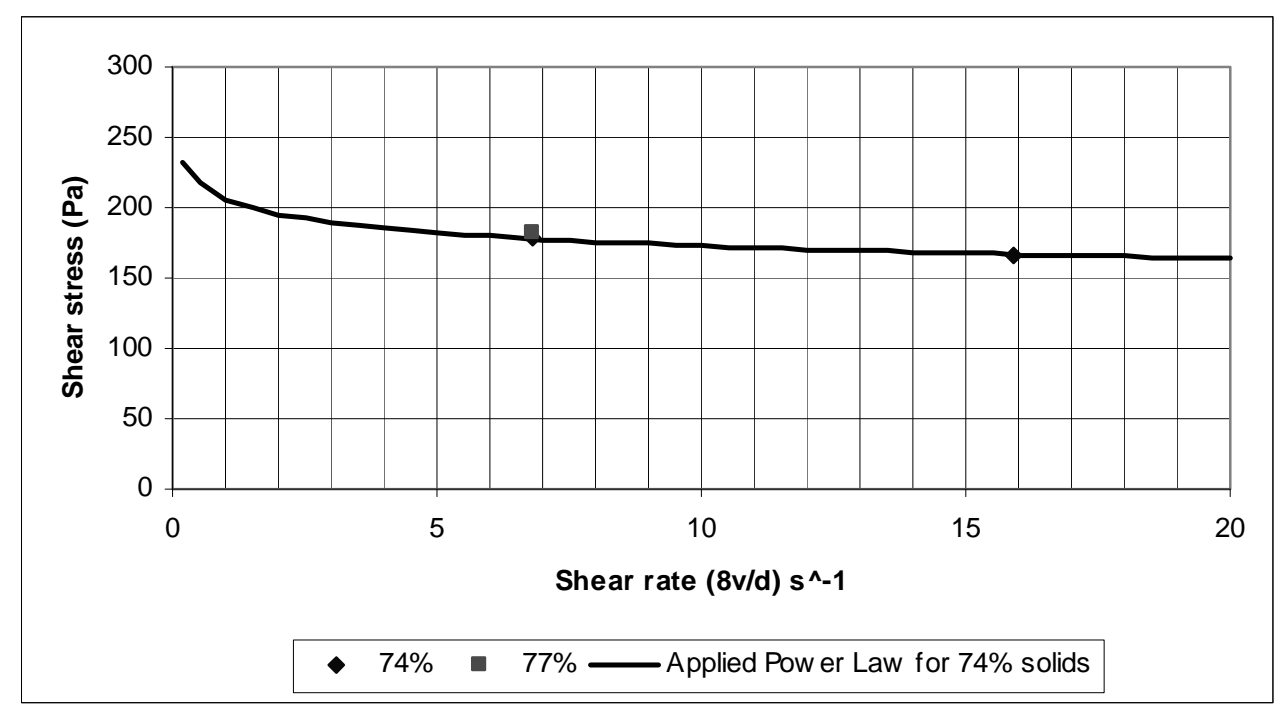

Figure 6 Shear stress versus shear rate from the trial depositions

If the full scale operation were to discharge tailings at 1200 tph and $73.7 \%$ solids $\left(1.8 \mathrm{t} / \mathrm{m}^{3}\right)$ through a $450 \mathrm{~mm}$ pipe with a residual pressure close to the discharge point of $100 \mathrm{kPa}$, and the pipe discharge were located $1.5 \mathrm{~m}$ above the beach level, the stream power at the edge of the plunge pool would be $19.7 \mathrm{~W}$, and the shear rate (calculated as $8 \mathrm{v} / \mathrm{R}$ ) $6.9 \mathrm{~s}^{-1}$. From Figure 2 this shear rate implies a shear stress in the flow stream of 201.4 Pa, and, from Equation (9), a friction slope at the lip of the plunge pool i.e. the initial slope of the beach, of 0.031 (1: 32.3). Over a beach length of $500 \mathrm{~m}$ the average beach slope would emerge as $1: 25.9(3.9 \%)$. 


\section{Conclusions}

The following conclusions may be reached from the information presented in this paper:

- The entropy-stream power approach is capable of simulating the beach profiles of flume-scale as well as full-scale beaching of both conventionally thickened and high density thickened tailings.

- Beach testing using small-scale flumes as well as pilot-scale trial depositions can be used effectively as large scale rheology tests from which to derive a settling slurry rheogram of shear stress versus shear rate using entropy-stream power-based calculations.

- Flume testing has the advantage of being able to evaluate a wider range of slurry densities but, due to practical limitations beaching in the flume will occur at higher shear rates than experienced at full scale. This will reduce the reliability of estimates of shear stress in the full scale operation although the accuracy is likely to be within the general accuracy of the beach predictions.

- Pilot-scale trial depositions are less flexible in terms of being able to evaluate a range of slurry densities but, provided flow rates and the deposition dimensions are set up in such a way that there is parity in the stream power gradient and shear rate with the full scale operation the predicted shear stress and therefore initial beach slope will be more reliable.

- The entropy-stream power approach, applied in conjunction with representative settling slurry-based estimates of the shear stress versus shear rate characteristics derived from small-scale beach testing, is versatile in predicting full scale beaching profiles.

- If small-scale flume or pilot-scale testing is carried out with a range of slurry densities it is possible to make a prediction of the full-scale beach profile from a knowledge of the full-scale pipe size, actual slurry density, flow rate, discharge conditions and beach length.

\section{References}

McPhail, G. (1995) Prediction of the beaching characteristics of hydraulically placed tailings, PhD Dissertation submitted to the University of the Witwatersrand, Johannesburg, South Africa.

Wasp, E.J., Kenny, J.P. and Gandhi, R.L. (1977) Solid-liquid flow slurry pipeline transportation, Trans Tech Publications, Germany.

Webber, N.B. (1971) Fluid Mechanics for Civil Engineers, Chapman and Hall, New York. 